\title{
As inundações do rio Douro em 1909: um contributo para o seu estudo a partir dos arquivos históricos da agência portuguesa do ambiente
}

\section{The 1909 river Douro flood: a contribution to its study from the historical archives of the portuguese environmental agency}

\author{
António Avelino Batista Vieira; Francisco da Silva Costa
}

\section{Resumo}

Entre os dias 17 e 25 de Dezembro de 1909, as populações da cidade do Porto e de Gaia assistiram, impotentes, à destruição das suas zonas ribeirinhas, por ação da cheia do rio Douro. A subida das águas provocou imensos prejuízos nas duas margens do Douro, obrigando à intervenção de diversos organismos do estado para a sua posterior reabilitação. A partir de alguns documentos do arquivo histórico da Agência Portuguesa do Ambiente, foi possível identificar as áreas afetadas por este evento catastrófico e a real amplitude dos seus efeitos nas zonas ribeirinhas do Porto e Gaia bem como a evolução dos trabalhos a partir daí.

Palavras-chave: Cheia, 1909, Rio Douro, Prejuízos, Informação histórica.

\begin{abstract}
Between 17 and 25 December 1909, the population of the city of Porto and Gaia watched helplessly the destruction of their riverside areas, by the flood of the Douro River. The flood caused immense losses on both banks of the Douro, forcing the intervention of various state agencies for their subsequent rehabilitation. From a set of documents of the authorship of the $1^{a}$ Direção dos Serviços Fluviais e Marítimos was possible to identify the interventions that were planned, as well as the progress of work, and, from there, also identify the areas affected by this catastrophic event and the real extent of their effects on riverside areas of Porto and Gaia.
\end{abstract}

Keywords: Floods, 1909, Douro river, Loss, Historical information.

Recibido el 18 de octubre de 2016, aceptado el 03 de mayo de 2017

Departamento de Geografia e CEGOT, Universidade do Minho, Campus de Azurém, 4800 Guimarães. Email: vieira@geografia.uminho.pt 


\section{Introdução}

A recolha e compilação de dados históricos das cheias constitui uma base indispensável para o estabelecimento das tendências do perigo ou dos desastres relacionados com as inundações (Aires, Pereira, \& Azevedo, 2000).

Dos diversos registos de catástrofes na área das inundações que, com maior ou menor impacte, causaram danos e consequências severas, deixando marcas na memória coletiva dos portugueses (Amaral, 1968;
Oliveira \& Ramos, 2002; Zêzere, Trigo, \& Trigo, 2005; Santos, Santos, \& Fragoso, 2015; Pereira, Ramos, Zêzere, Trigo, \& Vaquero, 2016), destaca-se a cheia de 1909 no rio Douro. No vale do Douro, tanto em território nacional, como em Espanha (Marquina, 1949; Pereira et al., 2016), encontram-se numerosas marcas que referenciam os níveis atingidos por esta grande inundação. Existem também referências escritas, de várias origens, sobre as localidades mais afetadas, o Porto, Vila Nova de Gaia e Peso da Régua (figura 1).

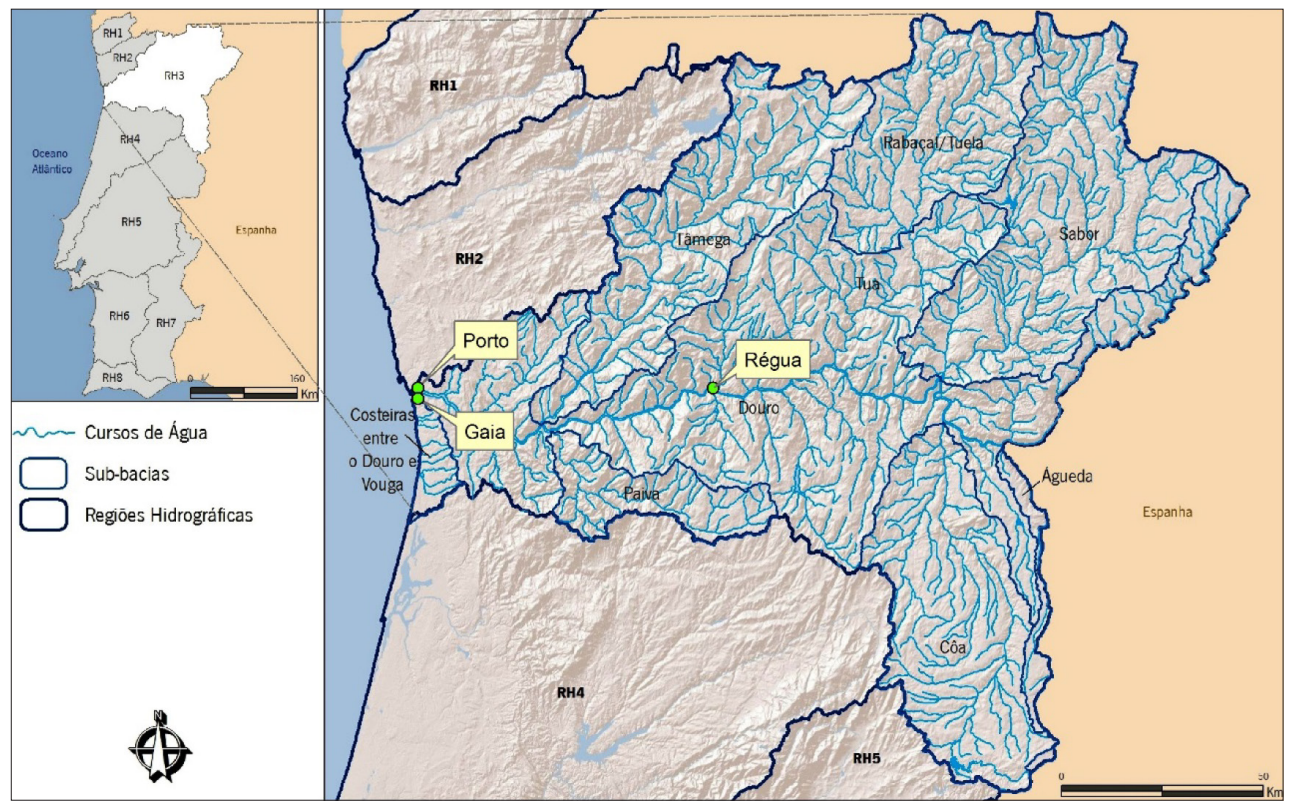

Figura 1. Região hidrográfica do rio Douro e respetivas sub-bacias em território nacional e localização do Porto, Gaia e Régua. Fonte: Adaptado de Zucco (2016)

Figure 1. Douro river hydrographic region and sub-basins in Portuguese territory, and localization of the cities of Oporto, Gaia and Régua. Source: Adapted from Zucco (2016)

Sem dúvida, esta cheia histórica está particularmente bem descrita, em virtude do seu impacte (APA 2016). Este evento extremo começou a provocar receios nas populações ribeirinhas afetadas a 17 de dezembro de 1909, com a progressiva subida das águas do Douro por efeito de precipitações intensas, galgando as margens do rio e começando a espalhar a destruição, a partir do dia 21 de Dezembro (figuras 2 e 3). Para além de inundar ruas e edifícios nas zonas ribeirinhas do Porto e de Gaia, provocando inclusivamente a destruição total ou parcial de inúmeras habitações, arrastou e destruiu (total ou parcialmente) cerca de 40 embarcações de médio e grande porte, mais de 700 pequenas embarcações de trafego fluvial (figuras 4 e 5), tendo também provocado 8 mortes. 

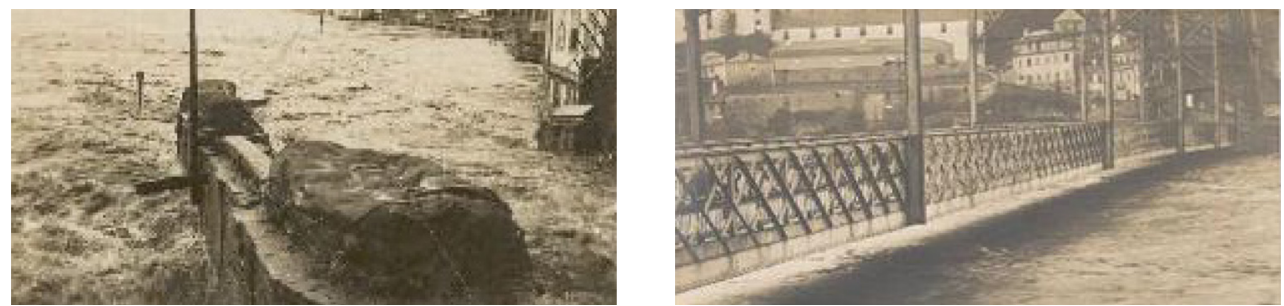

Figuras 2 e 3 . Aspeto tumultuoso das águas na zona da ribeira e nível observado junto à ponte D. Luís. Fonte: Arquivo Municipal do Porto.

Figures 2 and 3. Tumultuous aspect of the waters in the area of the Ribeira and level observed next to the D. Luís bridge. Source: Arquivo Municipal do Porto.
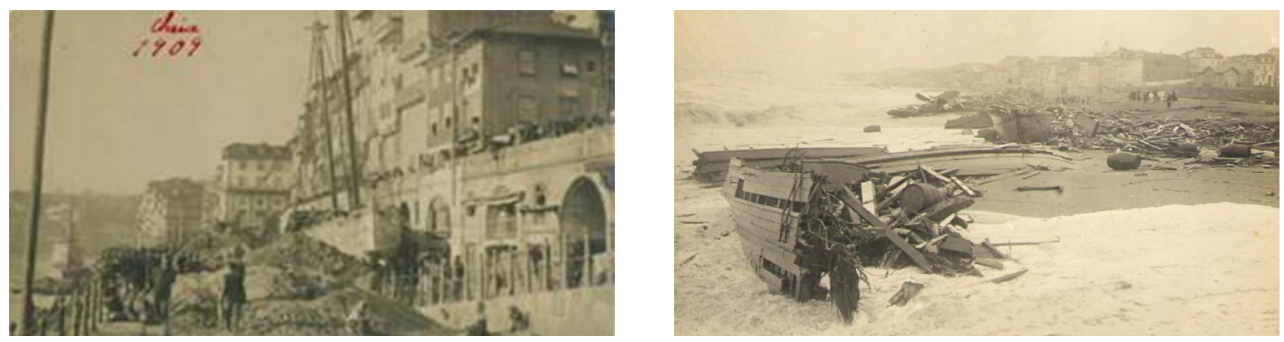

Figuras 4 e 5. Barcos encalhados e destruídos pela cheia. Fonte: Arquivo Municipal do Porto.

Figures 4 and 5. Boats stranded and destroyed by the flood. Source: Arquivo Municipal do Porto.

De facto, a amplitude desta cheia foi de tal forma que praticamente toda a zona ribeirinha do Porto ficou destruída. Também na margem oposta, em Gaia, o cenário se repetia, verificando-se a inundação de toda a zona ribeirinha. A altura da água atingida nesta cheia ficou ainda registada em diversas marcas colocadas em edifícios de ambas as margens do Douro (figuras 6 e 7).
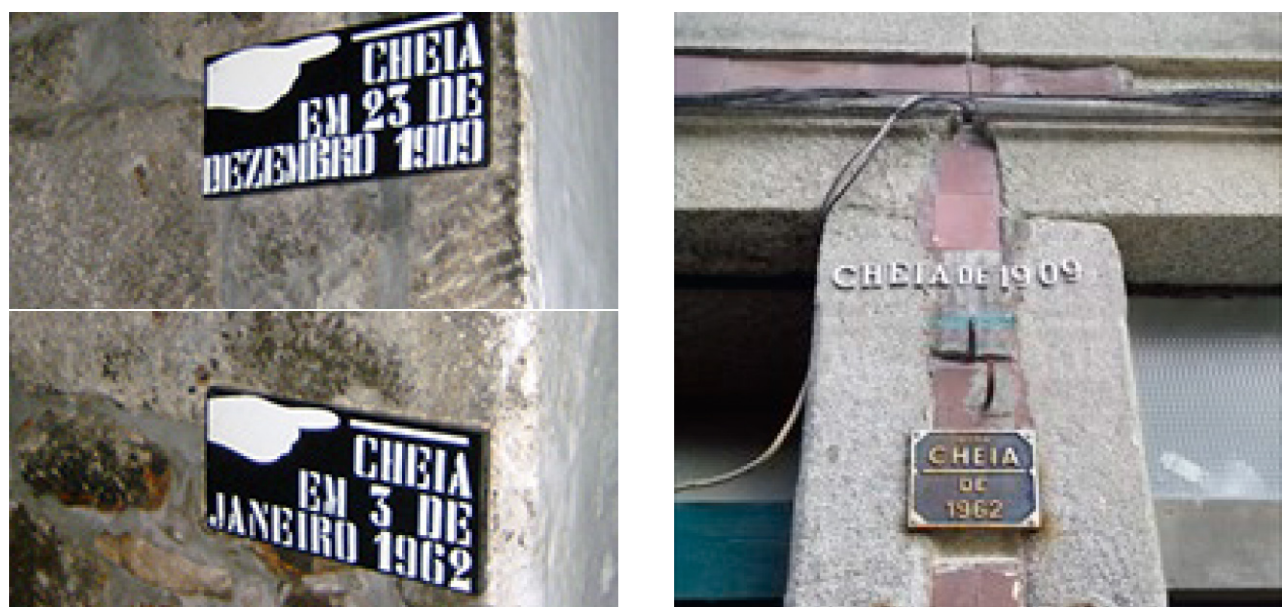

Figuras 6 e 7. Marcas da altura atingida pela cheia de 1909 em diversos edifícios. Fonte: Américo Brandão; Waymarking.com.

Figures 6 and 7. Marks of the height hit by the 1909 flood in various buildings. Source: Américo Brandão; Waymarking.com. 
No entanto, outras fontes históricas, nomeadamente as existentes no arquivo histórico da Agência Portuguesa do Ambiente, ainda pouco exploradas e utilizadas para o estudo dos eventos catastróficos que afetaram o território nacional desde o final do século XIX, encerram um manancial importante de informação de elevada relevância para o seu conhecimento. É, portanto, objetivo deste trabalho, recorrendo aos documentos presentes no referido arquivo, demonstrar a sua importância e o valor da informação histórico-arquivística, quer para o conhecimento do fenómeno em si, quer para a quantificação dos impactes económicos e para o conhecimento dos processos envolvidos na reabilitação das áreas afetadas pela cheia de 1909.

\section{Inundações no rio Douro: algumas considerações}

A região hidrográfica do rio Douro (figura 1) possui uma área de aproximadamente $79.000 \mathrm{~km}^{2}$, dos quais $18.643 \mathrm{~km}^{2}$ estão em território nacional $(20 \%)$ e $78.960 \mathrm{~km}^{2} \mathrm{em}$ Espanha (80\%).

De acordo com o Decreto-Lei n. ${ }^{\circ} 347 / 2007$, de 19 de Outubro, a região hidrográfica do rio Douro engloba a bacia hidrográfica do rio Douro, a bacia hidrográfica das ribeiras costeiras entre o Douro e o Vouga, incluindo as respetivas massas de águas subterrâneas, de transição e costeiras adjacentes (Zucco 2016). Esta região hidrográfica é composta por nove sub-bacias: Águeda, Côa, costeiras entre o Douro e o Vouga, Douro, Paiva, Rabaçal/Tuela, Sabor, Tâmega e Tua. A bacia hidrográfica do rio Douro é a maior da região hidrográfica $\left(6.027 \mathrm{~km}^{2}\right) \mathrm{e}$ abrange 55 concelhos. A principal linha de água é o rio Douro que nasce em Espanha, na serra do Urbión a cerca de 1.700 metros de altitude. Ao longo do seu curso (de 927 $\mathrm{km}$ ) atravessa o território espanhol numa extensão de $597 \mathrm{~km}$ e serve de fronteira ao longo de $122 \mathrm{~km}$, sendo os últimos $208 \mathrm{~km}$ percorridos em Portugal até à foz no Oceano Atlântico, entre as cidades do Porto e de Gaia. A parte norte de Portugal, onde o rio Douro se localiza, é uma região que apresenta elevados quantitativos de precipitação (1200-3000 mm/ano), embora com um regime bastante irregular, em termos interanuais e intermensais, condicionando de forma significativa o próprio regime dos rios (Ramos \& Reis, 2001).

Os registos sistemáticos dos níveis no curso nacional e internacional do rio Douro são relativamente recentes, sendo que a primeira escala data de 1915 e o primeiro limnígrafo de 1943. Contudo, dada a importância que as cheias têm para as populações ribeirinhas, existem registos de marcas de cheia dispersas ao longo do Douro, que permitiram a avaliação dos valores dos caudais máximos das maiores cheias ocorridas pelo menos desde o século XVIII (Silva \& Oliveira, 2002). A partir de então, as maiores cheias de que há memória no Douro nacional foram as de 1739 e 1909 (tabela 1).

Tabla 1

Caudais de ponta de cheias históricas do rio Douro, na Régua.

Table 1

Historical flood peak flow of the Douro river in Régua.

\begin{tabular}{llllll}
\hline Ano & $\begin{array}{l}\text { Caudal } \\
(\mathbf{m} 3 / \mathbf{s})\end{array}$ & Ano & $\begin{array}{l}\text { Caudal } \\
(\mathbf{m} 3 / \mathbf{s})\end{array}$ & Ano & $\begin{array}{l}\text { Caudal } \\
(\mathbf{m} 3 / \mathbf{s})\end{array}$ \\
\cline { 2 - 6 } $\mathbf{1 7 2 7}$ & 14000 & $\mathbf{1 8 4 3}$ & 13000 & $\mathbf{1 8 7 7}$ & 13500 \\
$\mathbf{1 7 3 9}$ & 18000 & $\mathbf{1 8 5 0}$ & 13900 & $\mathbf{1 8 8 8}$ & 11800 \\
$\mathbf{1 7 8 8}$ & 15500 & $\mathbf{1 8 5 5}$ & 12500 & $\mathbf{1 9 0 9}$ & 16700 \\
\hline $\mathbf{1 8 2 3}$ & 15600 & $\mathbf{1 8 6 0}$ & 15100 & & \\
\hline
\end{tabular}

Fonte: Silva \& Oliveira (2002) 
Como ponto de referência da excecionalidade das cheias é utilizada a cidade da Régua, não só pela convivência ancestral que o lugar mantém com as cheias do Douro (sendo, portanto, fonte de informação histórica valiosa), como por refletir já as características principais da drenagem de cheias na bacia (Rodrigues, Brandão, \& Costa, 2003).

\section{O recurso a fontes primárias existentes em arquivos para a reconstrução de eventos catastróficos passados}

A Agência Portuguesa do Ambiente é a entidade possuidora de um valioso arquivo resultante da atividade centenária desenvolvida pelos Serviços Hidráulicos, com tutela sobre a gestão da água e o planeamento dos recursos hídricos, que importa conhecer e divulgar. $\mathrm{O}$ acervo documental e técnico dos antigos Serviços Hidráulicos do Douro constitui uma oportunidade para entendermos uma Instituição Pública, onde a água e o seu uso marcam profundamente as relações sociais e as atividades económicas (Campelo, 2011; Costa 2010, 2011, 2012; Costa \& Cordeiro 2012, 2015; Costa, Cordeiro, Vieira, \& Silva, 2015), permitindo-nos também a recolha de informações acerca da ocorrência de fenómenos extremos relacionados com a água e que tinham impacte direto ou indireto sobre a gestão dos recursos hídricos e áreas envolventes.

São várias as áreas temáticas de interesse científico (histórico, geográfico, técnico, etc) tidas em conta na análise dos processos existentes neste arquivo, bem como os problemas, impactes e condicionantes das atividades humanas para a gestão do Domínio Público Hídrico (DPH), nas quais destacamos o exemplo das cheias e inundações no rio Douro.

A análise deste enorme espólio, autêntico manancial de informação para o conhecimento do passado recente, assenta forçosamente num estudo interdisciplinar e qualitativo, que abrange a pesquisa bibliográfica e documental.

São várias as formas de abordagens documentais utilizadas para ter-se acesso ao contexto histórico de determinado período estudado. As fontes primárias escritas são testemunhas do passado, "pegadas" deixadas na história pela ação dos homens, que o investigador utiliza para reconstruir a memória o mais próximo possível do que aconteceu (Ketelaar, 2004; Milligan, 1979). Documentos jurídicos (constituições, leis, decretos), sentenças, correspondência, inventários, censos, mapas, gráficos, são algumas das fontes primárias que podemos encontrar em arquivos e departamentos vinculados aos órgãos públicos que mantêm a prática do arquivamento de documentos. No entanto, é importante perceber que os documentos históricos só se tornam fontes primárias quando são utilizados na investigação.

Numa pesquisa qualitativa, é importante demonstrar o processo que conduziu às conclusões alcançadas, a fim de deixar claras as operações, por meio de uma descrição explícita e sistemática de todas as etapas do processo, que vai desde a seleção e definição dos problemas até os resultados finais que fundamentam as conclusões. Becker (1999) nomeia este processo de história natural das conclusões. Para ele, este método permite que outros estudiosos acompanhem os detalhes da análise realizada, bem como verifiquem como e em que bases o pesquisador chegou às suas conclusões, dando a oportunidade a outros pesquisadores fazerem seus próprios julgamentos quanto à adequação da prova e ao grau de confiança a ser atribuído à pesquisa.

Realizamos pesquisa bibliográfica sobre o tema, envolvendo aspetos relacionados com as inundações no rio Douro mas sobretudo uma pesquisa documental e fotográfica, que, segundo Gil (2012), se assemelha à pesquisa bibliográfica. Baseia- 
se, principalmente, em fontes ainda não organizadas, no caso, tratamento analítico e publicação específica, ou que ainda podem ser reelaboradas de acordo com os objetivos da pesquisa. No presente trabalho, a pesquisa documental debruçou-se sobre as inundações e contemplou um Estudo de Caso com o objetivo de reunir o maior número de informações possíveis, por meio de diferentes técnicas de investigação, a fim de apreender a totalidade de uma situação e descrever a complexidade de um caso concreto. "Através de um mergulho profundo e exaustivo num objeto delimitado, o estudo de caso possibilita a penetração na realidade social, não conseguida pela análise estatística" (Goldenberg, 2013: 34).

"A fotografia constitui também uma fonte importante na apreensão da realidade e na construção do conhecimento e enriquecimento cultural, passando a ser mais uma fonte a utilizar e juntar-se ao grupo dos textos, mapas, cartas, plantas, croquis, maquetes, etc." (Lopes, 2012: 18) pois é indesmentível a riqueza de conteúdos a serem explorados através de uma única fotografia.

O uso de documentos históricos para a reconstrução dos eventos extremos tem resultado num maior conhecimento destes fenómenos, como se constata pelos trabalhos de Azevedo, Nunes, Ramos (2004), no estudo das inundações no rio Tejo, de Sarmento \& Cardoso (2006), nos efeitos do terramoto de 1755 na laguna de Aveiro, ou de Taborda (2006), na reconstituição do temporal de 1739 .

\section{A pertinência da informação histórica na compreensão das inundações no rio Douro: o exemplo do arquivo dos Serviços Hidráulicos}

A investigação de inundações esbate, frequentemente, com dificuldades na obtenção de registos escritos, fotográficos ou de outra natureza (Correia,
Fordham, Saraiva, \& Bernardo, 1998). A excecionalidade de alguns eventos e o elevado grau de destruição que causaram em habitações e infraestruturas nas cidades do Porto e Gaia, mobilizou diversos serviços estatais, que produziram documentação com informação valiosa para a reconstrução, ainda que apenas parcial, das suas consequências.

Sendo a Agência Portuguesa do Ambiente (APA) proprietária do arquivo histórico e do espólio hidrométrico e pluviométrico dos Serviços Hidráulicos, que contam já com 130 anos, importa dar a conhecer alguns dos registos históricos para reforço da memória popular (Rodrigues et. al., 2003).

O primeiro processo sobre cheias que encontramos no arquivo da Agência Portuguesa do Ambiente (APA-ARHN) é datado de 1900. Num total de dez folhas, o processo.$^{\circ} 8$ de 1900 apresenta alguns telegramas e notas de serviço que relatam, de forma resumida, a evolução da inundação que afetou a secção inferior do rio Douro entre os dias 12 e 15 de fevereiro de 1900. No telegrama enviado a 12 de fevereiro ao Diretor Geral das Obras Públicas e Minas, o Eng. ${ }^{\circ}$ Chefe do Serviço dos Vales do Douro Inferior, informa que “...esta noite, uma grande cheia repentina causou desastres de importância aos navios...no rio Douro... Não se consta terem havido desgraças pessoais, tendo sido salvas algumas pessoas com aparelho porta-cabos...". No dia seguinte, com o relato entre os mesmos intervenientes ficamos a saber que "... São grandes os prejuízos ao comércio e parece que há a lamentar duas perdas de vida." Dois dias depois a inundação ainda se fazia sentir com o nível das águas do rio Douro a diminuir "....apenas, cerca de $60 \mathrm{~cm}$, achando-se ainda 5,5 metros acima do nível da baixa-mar ordinária." Dos prejuízos identificados nos cais, escadas e linguetas, chega-nos a situação retratada pelo ofício do Presidente da Municipalidade de Gaia para o Eng. ${ }^{\circ}$ Chefe do Serviço dos Vales do Douro Inferior a 17 de fevereiro de 1900 , 
em que este alerta para a necessidade de “...remover provisoriamente para o largo ribeirinho...a grande porção de lodo e areias que a recente cheia depositou na via pública".

Neste processo, realçamos a nota de serviço n. ${ }^{\circ} 26$ de abril de 1900 , com a descrição da inundação que se deu na noite do 11 para 12 neste mesmo mês e que refere que “...o rio cresceu repentinamente, atingindo em poucas horas, uma altura tal que cobria o cais da Ribeira, e adquirindo a corrente uma velocidade grande, sem dúvida não inferior a 8 milhas por hora. Esta cheia repentina, que se atribuiu ao degelo das grandes camadas de neve, que anteriormente havia caído nas serras do interior do país e do país vizinho que formam a extensa bacia hidrográfica deste rio...originando grandes desastres materiais...e duas perdas de vidas...a cheia já baixou na Régua um metro...procedendo à limpeza dos cais e linguetas."

No que diz respeito às inundações de 1909 , o processo n. ${ }^{\circ} 97$ de 1910 da $1^{\text {a }}$ Direção dos Serviços Fluviais e Marítimos constituiu a inestimável fonte de informação que nos permitiu desenvolver este trabalho, fornecendo-nos informações precisas acerca dos trabalhos de reconstrução a desenvolver, permitindo-nos, consequentemente, perceber a dimensão da catástrofe. Trata-se de um processo com quarenta e um documentos, num total de 78 páginas, constituídos por ordens e notas de serviço, telegramas, correspondência oficial, notas internas, ofícios, expediente e relatórios.

Logo após as inundações, iniciaram-se os trabalhos de reparação, com a participação da força de pontoneiros, destacada para esta cidade a fim de cooperar na reparação e reconstrução de algumas obras. São várias as referências a este destacamento de pontoneiros, militares da Arma de Engenharia especializados em operações de transposição de cursos de águas, e que estiveram na reconstrução do cais da Estiva e das escadas da Rainha até ao mês de abril de 1910 (Vieira \& Costa, 2014).

Entre janeiro e março de 1910 verificaramse vários contratempos: a suspensão de trabalhos, a re-aplicação de verbas, a distribuição de fundos e a transferência de pessoal (Vieira \& Costa, 2014). A 10 de Março, o Ministério das Obras Públicas, Comércio e Indústria vem “...autorizar ao Diretor dos Serviços Fluviais e Marítimos a despender no corrente ano económico, pelas forças do cap. ${ }^{\circ} 10 .^{\circ}$ da despesa extraordinária a quantia total de 1830.290 reis, que em conformidade com os pedidos constantes das requisições de fundos n. ${ }^{\circ}$ s 20,21 , e 23 da aludida Direcção, é destinada à reparação de estragos causados pelas cheias nas margens do Douro". Ficou assim determinado o rápido cumprimento na distribuição de fundos para o ano económico de 1910 e reforçadas as verbas destinadas à conservação e reparação de obras a cargo da $2^{\mathrm{a}}$. Direcção dos Serviços Fluviais e Marítimos (Vieira \& Costa, 2014).

No mês seguinte é elaborado um documento de grande interesse e importância, designado de "Projeto de reparação-Estragos causados pela cheia de 23 dezembro de 1909", constituído pela Memória descritiva e justificativa, a medição da obra, o orçamento geral e detalhado e a série de preços. Todas estas peças foram elaboradas pelo Engenheiro ajudante em 4 abril de 1910 e relativo às duas margens afetadas pela cheia de dezembro de 1909, na cidade do Porto e em Vila Nova de Gaia. Com base nas informações extraídas desta documentação, foi possível efetuar a reconstrução cartográfica dos locais afetados e dos respetivos trabalhos de recuperação (figura 8), tendo como suporte cartográfico a Carta Topographica da Cidade do Porto, dirigida e levantada pelo General de Brigada Augusto Gerardo Telles Ferreira, datado de 1892. 


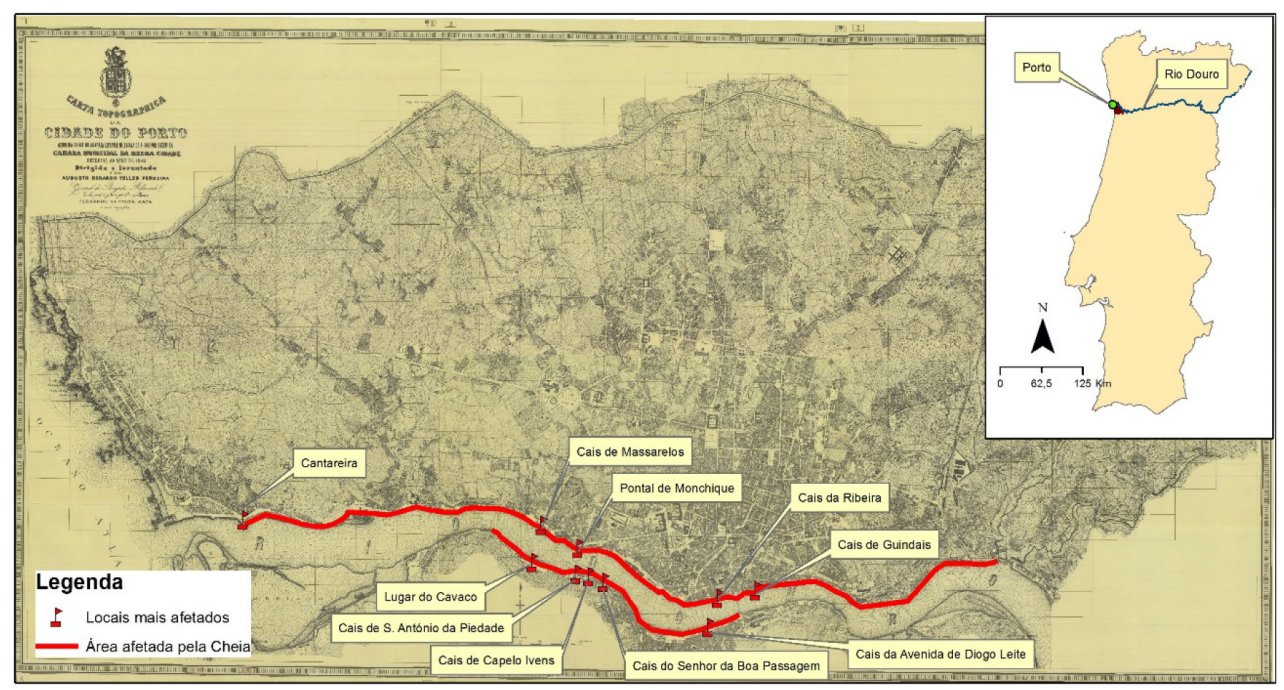

Figura 8. Localização dos pontos mais afetados referidos pelas inundações de 1909 no Porto e Gaia. Fontes: Carta Topographica da Cidade do Porto, de Augusto Gerardo Telles Ferreira (1892); Processo n. ${ }^{o} 97$ de 1910. Agência Portuguesa do Ambiente.

Figure 8. Location of the most affected areas referred to by the 1909 floods in Porto and Gaia. Sources: Topographical Chart of the City of Porto, by Augusto Gerardo Telles Ferreira (1892); Case No. 97 of 1910. Agência Portuguesa do Ambiente.

No que diz respeito à importância da informação, destacamos a memória descritiva e justificativa, que logo no seu preâmbulo refere que “...os estragos foram grandes e em tão diversos pontos que seria impossível e inútil fazer desde já um orçamento exato, não só porque muitas das obras devem ser reconstruídas segundo planos e projetos novos mas também porque o estado em que se encontram as suas fundações e perfil do leito do rio depois da cheia, é ainda desconhecido". Destacamos as principais avarias referidas com necessidade de intervenção imediata, por forma a proceder ao restabelecimento do trânsito e das condições normais dos serviços de carga e descarga de mercadorias (Vieira \& Costa, 2014). Assim, na margem direita verificaram-se:

Um rombo de 14 metros de comprido por 11 de alto no muro de suporte do $1^{\circ}$ lanço da atual estrada da circunvalação a jusante da Ponte D. Maria Pia. Esta avaria, devida à infraescavação das fundações, levou a interrupção do trânsito de carros e tornou perigoso o acesso aos peões.
$\mathrm{O}$ abatimento do muro de suporte à estrada junto ao Cais da Carqueja, tornando a passagem muito perigosa.

A destruição de toda a calçada argamassada em volta do encontro e de parte dos muros do cais dos Guindais, junto do encontro direito da Ponte D. Luiz I, comprometendo a solidez do encontro desta. As reparações desta avaria começaram imediatamente depois da cheia e já se encontravam terminadas, tendo-se construído $12,3 \mathrm{~m} 3$ de muro de cais, 205,65 m3 de calçada argamassada e empregado $210 \mathrm{~m} 3$ de aterro, num custo total de 581.175 réis.

A destruição de parte do muro a jusante do cais da Ribeira, já reparado, num montante de 107.355 réis.

A destruição em parte das Escadas das Padeiras e, em continuação destas, o seu patamar superior, uma lingueta e o seu patamar inferior, em parte da lingueta seguinte chamada da "Lenha", não se encontrando no local nada da cantaria em alvenaria que antigamente as compunham. 
A destruição das escadas da Rainha e, mais a jusante, a prancha e lingueta do cais da Estiva, reconstruídas pela companhia dos pontoneiros, tendo importado em 1485.055 réis.

As avarias produzidas na lingueta nova do cais da Estação do Porto A; foram ali reconstruídos $224 \mathrm{~m} 2$ de calçada à portuguesa.

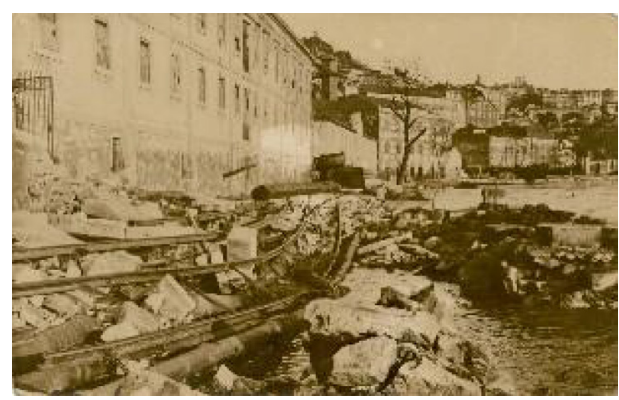

Os estragos no cais em Pontal de Monchique, devido aos choques das embarcações e à violência da corrente.

A violenta dragagem, desde o Pontal de Monchique até às escadas da Alfândega (figuras 9 e 10), levando à formação de um extenso banco de areia, justamente em frente do muro de cais por concluir, importando a sua reparação em 658.380 réis.

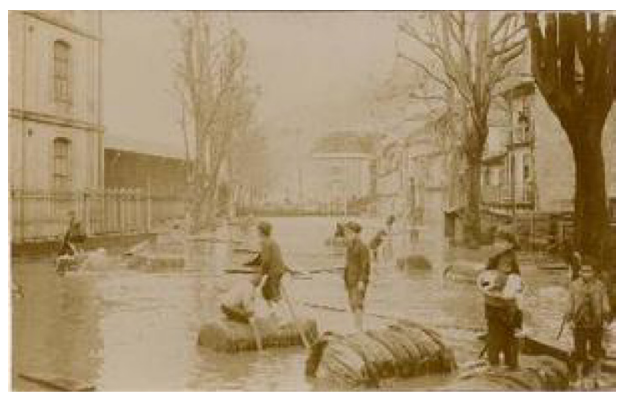

Figuras 9 e 10. Aspetos da inundação e destruição na zona da Alfầndega. Fonte: Arquivo Municipal do Porto.

Figures 9 and 10. Aspects of flooding and destruction in Alfầndega area. Source: Arquivo Municipal do Porto.

A destruição de uma lingueta em frente à Avenida de Massarelos, já reparada, importando a despesa ali feita em 129.665 réis.

A queda dos muros de cais desde Sobreiras à Cantareira, dos quais cerca de $8 \mathrm{~m} 3$ de pedra solta, tendo sido repostos e tendo custado essa reparação 154.625 réis.

O desabamento do $2^{\circ}$ lanço de estrada da circunvalação, já reparado.

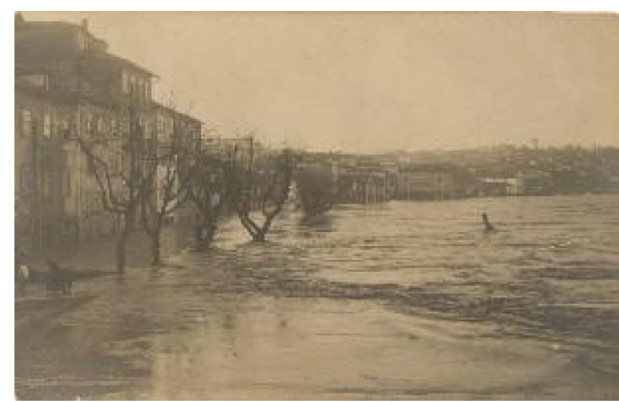

Figuras 11 e 12. Consequências da cheia na Avenida Diogo Leite. Fonte: Arquivo Municipal do Porto.

Figures 11 and 12. Consequences of the flood on Avenida Diogo Leite. Source: Arquivo Municipal do Porto.

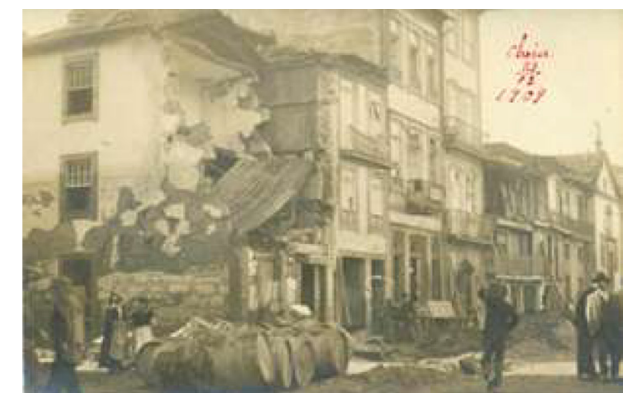

Os estragos produzidos pela cheia na margem esquerda foram maiores, destacando-se:

Aderrocada de todo o cais da Av. Diogo Leite e de $2 / 3$ da escadaria em frente do largo de D. Luiz, numa extensão total de cerca de 250 metros. A ação da corrente foi ali de tal forma violenta que dragou, até uma cota de cerca de $-3,5 \mathrm{~m}$, tendo a areia assoreado toda essa extensão de cais até quase à cota da preia-mar (figuras 11 e 12). 
A avaria e destruição do Cais de Capelo Ivens, principal via de comunicação entre os diversos bairros ribeirinhos de Gaia.
A danificação de todos os cais a jusante, nomeadamente o Cais Logan, no Lugar do Cavaco (figuras 13).

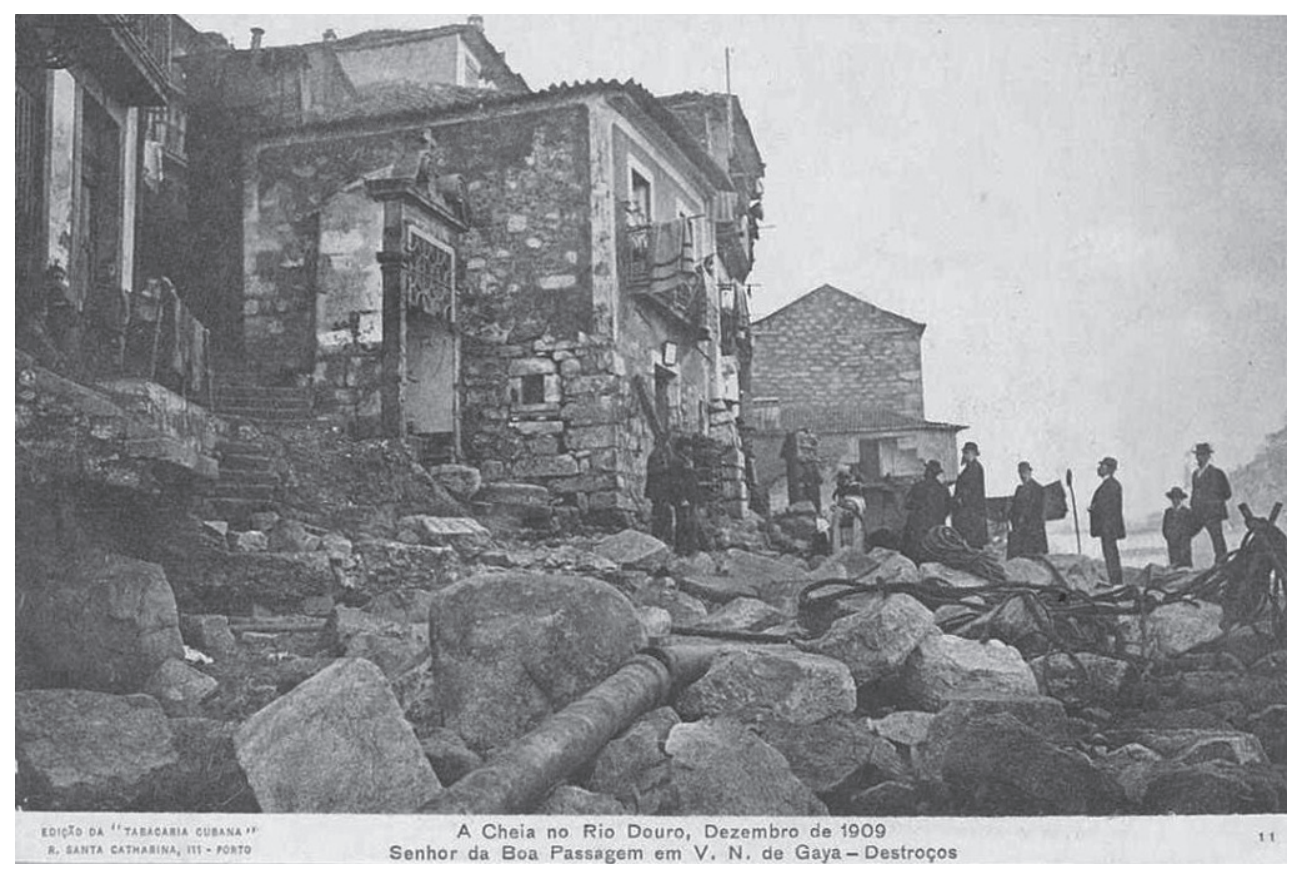

Figura 13. Aspeto da destruição provocada na margem de Gaia. Fonte: Arquivo Municipal do Porto.

Figure 13. Aspect of the destruction in the margin of Gaia. Source: Arquivo Municipal do Porto.

Este projeto também inclui documentos sobre o orçamento detalhado e a tipologia de obras a efetuar (tabela 1). O orçamento detalhado (em Réis - \$ - moeda em circulação em Portugal, à época) refere-se às reparações dos cais do Douro, incluídas no orçamento global já aprovado e ainda não efetuadas por falta da verba correspondente. $\mathrm{Na}$ margem direita e nos locais indicados foram determinados os seguintes custos: próximo à ponte $\mathrm{D}$. Maria Pia construção de $308 \mathrm{~m} 3$ de muro de cais e respetivos aterros -1275.200 réis; Escadas das Padeiras -95.040 réis; Patamar a jusante das escadas das padeiras -299.200 réis; Lingueta a jusante das escadas das padeiras -980.464 réis; Patamar inferior entre esta lingueta e a da Lenha -116.569 réis; Lingueta da Lenha destruída em parte -235.288 réis; muros do cais na Cantareira -814.250 réis, num total de 3816.011 réis.

Os valores orçamentados para a margem esquerda ascenderam a 5131.657 réis: calçada junto do encontro da ponte -18.000 réis; Muro da parte ajardinada sobre o encontro da antiga ponte pênsil -76.680 réis; Cais da Avenida Diogo Leite -716.000 réis; Calçada em frente do mercado -54.560 réis; Cais Capelo Ivens (parte ainda não reconstruída) -273.035 réis; Cais Senhor da Boa Passagem -428.560 réis; Cais das Fontainhas -853.840 réis; Cais de $\mathrm{S}$. António do Vale da Piedade -1501.660 réis; Cais Logan -1209.322 réis.

A importância prevista com as reparações até ao fim do ano económico 1909-1910 era 
de 7003.375 réis, num orçamento global previsto de 16000.000 réis (tabela 2). O ponto de situação relativo ao orçamento das reparações dos cais do Douro apontava para o facto de não terem sido efetuadas a maior parte das obras por falta da verba correspondente. A 25 de Abril de 1910, três meses depois da cheia, as reparações já efetuadas ascendiam somente ao valor de 4354.225 réis.

Tabla 2

Relação das obras previstas por tipologia e seus custos (em Réis)

Table 2

List of planned works by type and their costs (in Réis)

\begin{tabular}{|c|c|c|c|}
\hline Designação da obra & Preço Valor & Quantidade $\left(\mathrm{m}^{3}\right)$ & Por artigos \\
\hline \multicolumn{4}{|l|}{ Obra de pedreiro na margem direita } \\
\hline Alvenaria e cantaria hidráulica & 4000 & 1244.288 & 4977.152 \\
\hline Alvenaria de pedra seca & 2000 & 300 & 600.000 \\
\hline Cantaria em degraus & 10000 & 19.873 & 198.720 \\
\hline Aterro & 120 & 4318.660 & 518.239 \\
\hline Calçada à portuguesa & 400 & 538.500 & 215,400 \\
\hline Calçada argamassada & 600 & 339.016 & 203.409 \\
\hline \multicolumn{4}{|l|}{ Obra de carpintaria na margem direita } \\
\hline $\begin{array}{l}\text { Reconstrução da lingueta e prancha de } \\
\text { estiva }\end{array}$ & & & 1485.055 \\
\hline Reconstrução das escadas da Rainha & & & 450.000 \\
\hline \multicolumn{4}{|l|}{ Obra de pedreiro na margem esquerda } \\
\hline Alvenaria e cantaria hidráulica & 4000 & 1467.600 & 5870.400 \\
\hline Aterro & 120 & 3835.180 & 460.341 \\
\hline Calçada à portuguesa & 400 & 955.400 & 382.160 \\
\hline Calçada argamassada & 600 & 495.750 & 297.450 \\
\hline \multicolumn{4}{|l|}{ Remoção de areia e lodos } \\
\hline Lodo e areia acumulado nos cais & 100 & 2500 & \\
\hline Orçamento & & & 16000.000 \\
\hline
\end{tabular}

No que se refere ao tipo, dimensão e custo de obra a efetuar, destacam-se os trabalhos de pedra, carpintaria e a remoção de areias e lodo (tabela 2). Os trabalhos de construção civil iniciaram-se logo após a catástrofe, enquanto que somente em agosto de 1910 foi solicitada a aquisição ou vinda ao Douro de uma draga de sucção para restabelecer a passagem pelo canal da barra e facilitar o acesso ao porto. Coube à Junta das Obras da
Barra do Douro renegociar com uma firma espanhola esta obra, já que esta se tinha oferecido para executar essa dragagem (Vieira \& Costa, 2014).

Somente em julho de 1910 foi aprovado o orçamento apresentado a 4 de abril sobre as grandes reparações nos cais e margens do rio Douro e confirmado o valor de 16000.000 réis. Nesta altura o ponto de situação sobre 
as obras em falta mostra que orçamento ascendia a um valor de quase nove mil reis e, por isso, superior ao valor das reparações já entretanto efetuadas (tabela 3 ).

Tabla 3

Relação dos locais a ser reabilitados e orçamentação das obras (em Réis).

Table 3

List of sites to be rehabilitated and budgeting of works (in Réis).

\begin{tabular}{|c|c|}
\hline Designação das obras & $\begin{array}{l}\text { Importâncias constantes do } \\
\text { orçamento aprovado por Portaria } \\
\text { de } 18.7 .1910\end{array}$ \\
\hline $\begin{array}{l}\text { Próximo à ponte D. }{ }^{a} \text { Maria Pia-Construção de } 308 \mathrm{~m} 3 \text { de muro } \\
\text { de cais e respetivos aterros }\end{array}$ & 1275.200 \\
\hline Escadas das Padeiras & 95.040 \\
\hline Patamar a jusante das Padeiras & 299.200 \\
\hline Lingueta a jusante das escadas das Padeiras & 980.464 \\
\hline Patamar inferior entre esta lingueta e a da Lenha & 116.569 \\
\hline Lingueta da Lenha (destruída em parte) & 235.288 \\
\hline Muros de cais na Cantareira & 814.250 \\
\hline Total margem direita & 3816.011 \\
\hline Calçada junto do encontro da ponte & 18.000 \\
\hline $\begin{array}{l}\text { Muro da parte ajardinada sobre o encontro da antiga ponte } \\
\text { pensil }\end{array}$ & 76.680 \\
\hline Cais da Avenida Diogo Leite & 716.000 \\
\hline Calçada em frente do mercado & 54.560 \\
\hline Cais Capelo Ivens (parte ainda não reconstruída) & 273.035 \\
\hline Cais do Senhor da Boa Passagem & 428.560 \\
\hline Cais das Fontainhas & 853.840 \\
\hline Cais de S. António do Vale da Piedade & 1501.660 \\
\hline Cais Logan & 1209.322 \\
\hline Total margem esquerda & 5131.657 \\
\hline Total 2 margens & 8947.668 \\
\hline
\end{tabular}

As obras na margem esquerda continuavam atrasadas, de tal forma que o próprio presidente da Câmara Municipal de Vila Nova de Gaia, numa carta enviada ao Ministro do Fomento a 30 de novembro de 1910, lamenta "...o estado verdadeiramente desgraçado em que se encontra a margem esquerda do rio Douro, a qual compreende todo o litoral desta vila e cujos cais ficaram no mais lastimável estado de ruína, em virtude da última cheia em dezembro de 1909." Face a esta situação, o autarca reclama urgência “... no estudo dos mesmos cais, a fim de que, sem perda de tempo, sejam devidamente reparados, porquanto, no estado de ruína em que se acham causam ao comércio os mais graves e extraordinários prejuízos... 
da ligação da vila propriamente dita, com o importante lugar de Afurada...da melhor forma de amarração das embarcações de maneira a evitar que as correntes e cabos tornem intransitável os referidos cais principalmente para os carros, sendo também um perigo para as pessoas que por ali sejam obrigados a transitar...".

Os documentos arquivados no processo 97 de 1910 não nos permitem saber quando terminaram as obras e o custo real das mesmas. No entanto, fica claro que a gestão da crise do ponto de vista institucional foi complexa e demorada. No último documento do processo temos acesso ao relatório enviado pelo apontador encarregado das cheias, Narciso Marques, ao diretor geral da $1^{\text {a }}$ Direção dos Serviços Fluviais e Marítimos e que permite comparar o nível de cheia entre 1909 (26,3 m), 1910 (19,6 m) e 1860 (24,46 m), verificados na Ponte da Régua.
Esta informação é completadas pelos registos que encontramos no processo $\mathrm{n}^{\circ} 7$ de 1910. Através de várias comunicações internas dirigidas ao chefe de departamento marítimo do Porto e notas de serviços dirigidas ao engenheiro chefe da $4^{\mathrm{a}}$ secção, Narciso Marques descreve a evolução da altura das cheias do rio Douro ao longo de 1909. Desde 1904, os guarda-rios tinham a tarefa de fazer o acompanhamento da subida das águas referente às cheias do Douro entre a Régua, Pinhão e Barca de Alva e reportar a Narciso Marques "qualquer alteração nas águas do rio Douro, para poder informar cabalmente o Departamento Marítimo nessa cidade." (Nota de serviço n. ${ }^{\circ} 3$ de 12 de março de 1909).

A partir dos telegramas diários enviados por Narciso Marques entre o 15 e 30 de dezembro de 1909, é possível fazer a cronologia dos registos de subida das águas do rio Douro (figure 14).

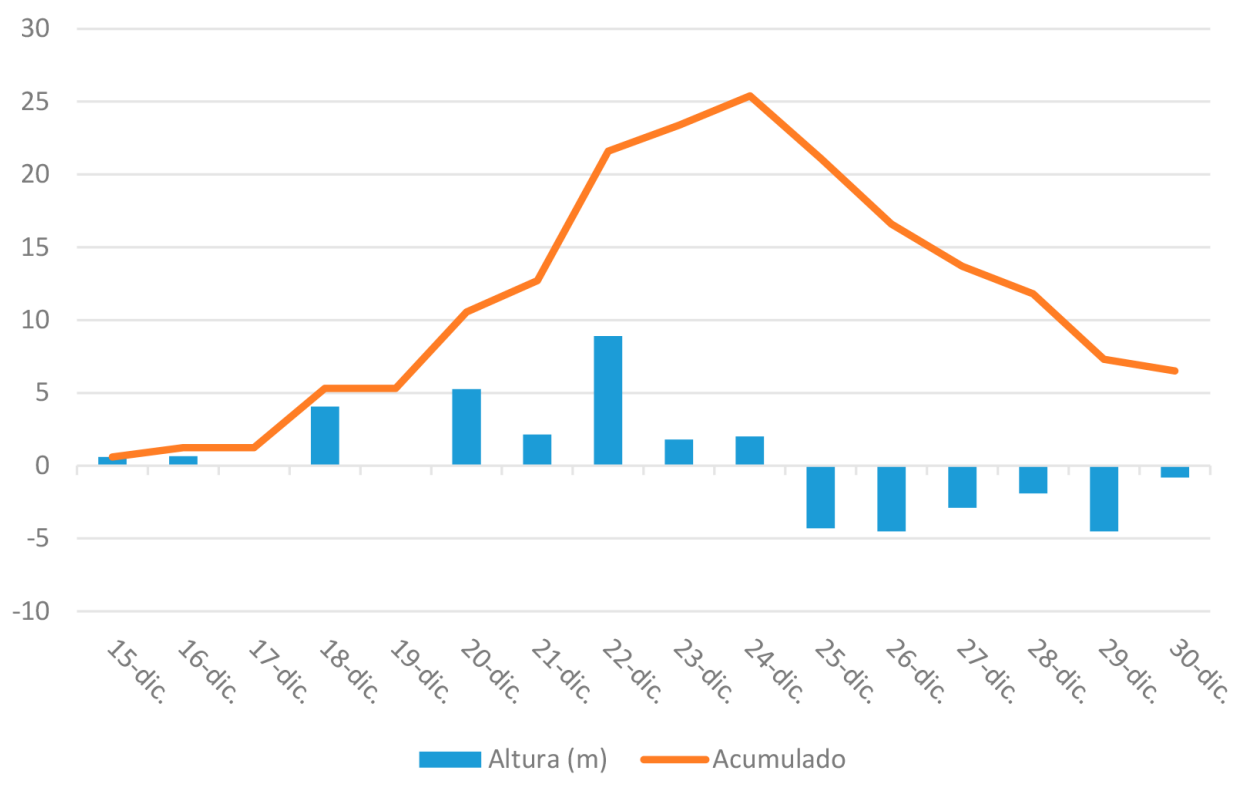

Figura 14. Evolução da altura das águas na Régua entre 15 e 30 de Dezembro de 1909. Fonte: Agência Portuguesa do Ambiente.

Figure 14. Evolution of the level of the flood in the Régua between 15 and 30 of December of 1909. Source: Agência Portuguesa do Ambiente. 
Narciso Marques informa a 28 de dezembro ao seu superior que a maior altura foi de 26,30 m. Embora estes dados sejam relativos à altura das águas na Régua, estimamos que a situação na foz do rio Douro, entre Porto e Gaia, tenha sido ainda mais gravosa, conforme constatamos através do processo n. ${ }^{\circ} 97$ de 1910.
Rodrigues et. al. (2003) trazem um contributo importante com a elaboração do hidrograma para a inundação de 1909, onde é possível identificar os picos de cheios ocorridos a 23 e 25 de dezembro (figura 15).

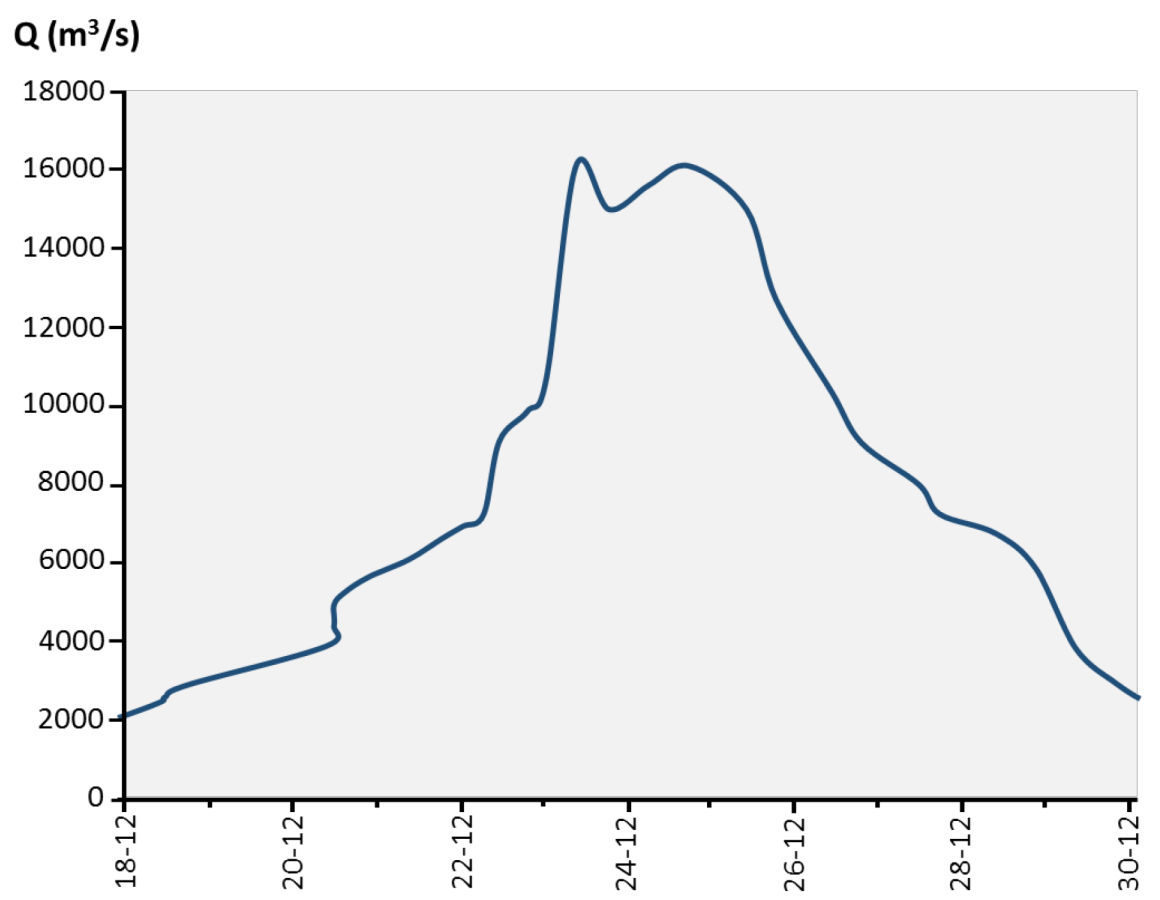

Figura 15. Histograma da cheia de 1909. Fonte: Adaptado de Rodrigues, Brandão e Costa (2003)

Figure 15. Histogram of the 1909 flood. Source: Adapted from Rodrigues, Brandão and Costa (2003)

O registo histórico refere, em geral, as cheias que se revestiram de carácter extraordinário, não havendo memória daquelas que, com carácter anual, não provocaram prejuízos. O critério para a classificação das cheias do Douro em extraordinárias ou normais está bem definido. Na foz do rio designamse cheias extraordinárias as cheias que ultrapassam a cota dos $+6,00 \mathrm{~m}$, medidos junto à ponte de $\mathrm{D}$. Luis, na margem direita, por serem aquelas que galgam o cais da Ribeira ( $\operatorname{cota}+5,90 \mathrm{~m}$ ), embora quando isso sucede, já Miragaia está inundada $(+4,19$ $\mathrm{m})$. Relativamente ao Peso da Régua, são consideradas cheias extraordinárias aquelas que inundam a Avenida João Franco (cota a $58 \mathrm{~m}$ ), implicando uma subida do nível do rio de $13 \mathrm{~m}$ (caudal a $6000 \mathrm{~m} 3 / \mathrm{s}$ ) (Aires et. al., 2000).

\section{Conclusões}

A cheia ocorrida no Douro, em dezembro de 1909 é considerada uma das maiores e mais destrutiva que afetou as zonas ribeirinhas do Porto e de Gaia. Os trabalhos de reconstrução e reabilitação das áreas afetadas revelou-se bastante demorado, especialmente na margem de Gaia, onde, quase um ano depois, várias obras ainda 
estavam por realizar. Acresce a essa demora o facto de Portugal atravessar um período bastante conturbado, do ponto de vista político e social, que culminou com a implantação da República, a 5 de outubro de 1910

Dos vários documentos consultados no arquivo histórico da APA-ARHN, destacamos o Processo 97 de 1910, elaborado pela $1^{\text {a }}$ Direção dos Serviços Marítimos e Fluviais, pelas importantes informações que transmite relativas aos trabalhos planeados, sua orçamentação, percalços na execução das diversas intervenções, permitindo, ainda, a identificação dos impactes da cheia, áreas afetadas e prejuízos registados.

Do trabalho apresentado é fundamental realçar a importância que as fontes documentais representam enquanto informação fulcral para a reconstituição de eventos passados, como é o exemplo a cheia do Rio Douro em 1909. Á luz das ciências geocindínicas podemos afirmar que os documentos encontrados no arquivo histórico da APA-ARHN trazem um vasto conjunto de informações de grande interesse no âmbito do risco de inundação, vulnerabilidade das infraestruturas e exposição das áreas afetadas.

A riqueza documental do arquivo da APA e suas potencialidades no âmbito da investigação permitem estudos diversificados, quer no domínio da Geografia, das ciências históricas, do património, do planeamento e também em alguns campos da arqueologia, da hidráulica e hidrologia. Garantir a sua conservação é essencial, pelo que a sua gestão integrada e sua institucionalização é um passo importante na defesa de uma memória comum que urge preservar (Costa \& Cordeiro, 2012).

\section{Bibliografia}

Aires, C., Pereira, D., \& Azevedo, T. (outubro, 2000). Inundações do rio Douro: dados históricos e hidrológicos. Trabajo presentado en la I Jornadas do Quaternário da APEQ, Porto, FLUP. Resumen recuperado de http:// web.letras.up.pt/asaraujo/APEQ/p11.html.
Amaral, I. (1968). As inundações de 25/26 de novembro de 1967 na região de Lisboa. Finisterra, Revista de Geografia Portuguesa, 3 (5), $79-84$.

Agência Portuguesa do Ambiente, APA (2016). Plano de Gestão dos Riscos de Inundações, 2016 - 2021. Região Hidrográfica 3-Douro. Zonas Críticas: Régua, Porto/Vila Nova de Gaia e Chaves.

Azevedo, T.M., Nunes, E., \& Ramos, C. (2004). Some morphological aspects and hydrological characterization of the Tagus floods in the Santarém region, Portugal. Natural Hazards, 31, 587-601.

Becker, H.S. (1999). Métodos de pesquisa em ciências sociais. São Paulo: Hucitec.

Campelo, A. (2011). Das hidráulicas aos recursos hídricos: história, sociedade $e$ saber. Porto: ARH do Norte.

Correia, F. N., Fordham, M., Saraiva, M. G., \& Bernardo, F. (1998) Flood hazard assessment and management: Interface with the public. Water Resources Management, 12(3), 209-227. https://doi. org/10.1023/a:1008092302962

Costa, F.S. (2012). O arquivo da administração da região hidrográfica do norte: roteiro metodológico. In M. Martins, I. Vaz de Freitas, M.I. Del val Valdivieso (Coords.). Caminhos da água. Paisagens e usos na longa duração. (pp. 267-293). Braga: CITCEM. Centro de investigação transdisciplinar. Cultura, espaço e memória.

Costa, F.S. (2011). Licenciamento em águas públicas e cartografia: o caso do Rio Ave no início do século XX. In N. Santos e L. Cunha (Ed.) Trunfos de uma geografia activa: desenvolvimento local, ambiente, ordenamento e tecnologia (pp. 593-602). Coimbra: Universidade de Coimbra.

Costa, F.S. (2010). Águas públicas e sua utilização no concelho de Fafe: um contributo do ponto de vista históricogeográfico. Fafe: Câmara Municipal de Fafe.

Costa, F.S. \& Cordeiro, J.M.L. (2012). O CEDOCAVE. Centro de Documentação sobre Água no Cávado e Ave: um projeto para 
preservar a memória e divulgar o património e cultura da água. Atas das VIII Jornadas de Geografia e Planeamento Cidades, criatividade(s) e sustentabilidade(s) (pp. 21-28). Guimarães: Universidade do Minho.

Costa, F.S., Cordeiro, J.M.L. (2015). ArchivAVE: Património documental da bacia do Ave. Guimarães: Universidade do Minho.

Costa, F.S., Cordeiro, J.M.L., Vieira, A.A.B., \& Silva, C.C.S. (2015). ArchivAve: um projeto para conservar e divulgar o património documental do rio Ave. Atas 4 do II Simpósio de Pesquisa em Geografia, Universidade do Minho y Universidade Federal de Santa Maria (pp.50 - 63). Guimarãe: Universidade do Minho.

Gil, A.C. (2012). Métodos e técnicas de pesquisa social. São Paulo: Atlas.

Goldenberg, M. (2013). A arte de pesquisar: como fazer pesquisa qualitativa em ciências sociais. Rio de Janeiro: Record.

Ketelaar, E. (2004). Time future contained in time past: archival science in the $21 \mathrm{st}$ century. Journal of the Japan Society for Archival Science 1, 20-35.

Lopes, I.(2012). Asfotografias na construção das conceções de emigração: um estudo com alunos do 3. ${ }^{\circ}$ ciclo do Ensino Básico. (Dissertação de mestrado em ciências da educação, área de especialização em supervisão pedagógica na educação em história e ciências sociais). Instituto de Educação da Universidade do Minho, Portugal.

Marquina, J.R. (1949). Crecidas extraordinárias del rio Duero. Revista de Obras Públicas, 202-213.

Milligan, J.D. (1979). The Treatment of an Historical Source. History and Theory 2, 177-196.

Oliveira, P.E. \& Ramos, C. (2002). Inundações na cidade de Lisboa durante o século XX e seus factores agravantes. Finisterra, XXXVII (74), 33-54.

Pereira, S., Ramos, A.M., Zêzere, J.L., Trigo, R.M., \& Vaquero, J.M. (2016). Spatial impact and triggering conditions of the exceptional hydro-geomorphological event of December 1909 in Iberia. Nat. Natural Hazards and
Earth System Sciences, 16 (2), 371-390. https://doi.org/10.5194/nhess-16-371-2016

Ramos, C. \& Reis, E. (2001). As cheias no sul de Portugal em diferentes tipos de bacias hidrográficas. Finisterra, XXXVI (71), 61-82.

Rodrigues, R., Brandão, C., \& Costa, J. (2003). As cheias no Douro ontem hoje e amanhã. Lisboa: Ministério das cidades ordenamento do território e ambiente. Instituto nacional da água, direcção dos serviços de recursos hídricos.

Santos, M., Santos, J.A., \& Fragoso, M. (2015). Historical damaging flood records for 1871-2011 in northern Portugal and underlying atmospheric forcings. Journal of Hydrology, 530, 591-603. https://doi. org/10.1016/j.jhydrol.2015.10.011

Sarmento, C. \& Cardoso, A. (2006). Testemunhos históricos da influência do terramoto de 1755 na laguna de Aveiro. Territorium, 13, 93-104.

Silva, J. \& Oliveira, M. (2002). As cheias na parte portuguesa da bacia hidrográfica do rio Douro. Atas do $3{ }^{\circ}$ Congresso ibérico de gestão e planeamento da água. Sevilla: Fundação Nova Cultura da Água.

Taborda, J.P. (2006). O temporal de 3 a 6 de Dezembro de 1739 em Portugal. Reconstituição a partir de fontes documentais descritivas. Finisterra, XLI (82), 73-86.

Vieira, A. \& Costa, F. (2014). A cheia do Douro de 1909: consequências e medidas de recuperação nas áreas ribeirinhas do Porto e Gaia. Actas do VIII Simpósio LatinoAmericano da Geografia Física. (pp. 890898). Santiago: Universidade do Chile.

Zêzere J.L., Trigo R.M., \& Trigo I.F. (2005) Shallow and deep landslides induced by rainfall in the Lisbon region (Portugal): assessment of relationships with the north atlantic oscillation. Natural Hazards and Earth System Sciences, 5 (3), 331-344. https://doi.org/10.5194/nhess-5-331-2005

Zucco, E. (2016). Os Planos de Gestão de Região Hidrográfica em Portugal Continental: contributo para o desenvolvimento de um instrumento para a avaliação de planos de recursos hídricos. (Dissertação de doutoramento). Braga: Universidade do Minho. 